\title{
Çinko Düzeylerinin Ölçümünde Matriks Seçimi
}

\section{Matrix Selection for Measurement of Zinc Levels}

\section{Sema Kardeşler $\oplus$, Fatma Demet Arslan $\oplus$, İnanç Karakoyun $\oplus$, Banu İşbilen Başok $\oplus$, Ayfer Çolak $\oplus$}

Cite as: Kardeşler S, Arslan FD, Karakoyun İ, İşbilen Başok B, Çolak A. Çinko düzeylerinin ölçümünde matriks seçimi. Forbes J Med. 2020;1 (3):79-83.

öz

Amaç: Çinko, büyüme geriliği, immün yetmezlik, infertilite, nörolojik bozukluk, akrodermatitis enteropatika tanısı gibi durumlarda sıklıkla kullanılan bir testtir. Çinko düzeylerinin ölçümünde diğer testlerle birlikte analiz edilme kolaylığı ve serum eldesinde kullanılan kan alma tüplerinin maliyet etkinliği nedeniyle sıklıkla serum matriksi tercih edilmektedir. Çalışmamızda doğru ve güvenilir çinko sonuçları için standart pıhtı aktivatörlü jelli ve eser element için özel üretilmiş heparinli jelsiz tüplerdeki serum ve plazma çinko sonuçları karşılaştııılması amaçlanmıştır.

Yöntem: Çalışmaya rastgele seçilmiş 27 hasta dahil edildi. Hastalardan eş zamanlı hem pihtı aktivatörlü jelli tüplere (SST) (SST II Advance, Vacuteiner, Becton Dickinson and Company, Amerika), hem de sodyum heparin içeren eser element tüplerine ( $\mathrm{NH}$ ) ( $\mathrm{NH}$ Trace Elements Sodium Heparin, Vacuette, Greiner Bio-One $\mathrm{GmbH}$, Avusturya) kan alındı. Santrifüj sonrası elde edilen serum ve plazma örneklerinde çinko düzeyleri kolorimetrik yöntem ile otoanalizörde ölçüldü. Serum ve plazma çinko düzeyleri arasındaki bias biyolojik varyasyon kaynaklı izin verilebilir bias kriterine göre değerlendirildi ve regresyon analizi yapıldı.

Bulgular: Serum ve plazma çinko düzeylerinin ortalaması ve standart sapması sırasıyla $49.0 \pm 11.5 \mu \mathrm{g} / \mathrm{dL}$ ve $46.4 \pm 12.0 \mu \mathrm{g} / \mathrm{dL}$ olarak bulundu ve arasında istatistiksel olarak anlamlı fark saptandı $(p=0.012)$. Ayrıca serum ve plazma arasındaki bias $\% 6,8$ olup, izin verilebilir biasın $(\% 3,3)$ üzerindeydi ve klinik olarak anlamlı kabul edildi. Sistematik ya da rastlantısal hata saptanmadı.

Sonuç: Eser elementler ölçümü için kullanılacak kan alma tüpleri seçilirken yapısal farklılıklar ve matriks etkisi nedeniyle oluşabilecek farklılıklar göz önünde bulundurulmalıdır.

Anahtar kelimeler: Çinko, plazma, serum, örnek toplama

\section{ABSTRACT}

Objective: Measurement of blood zinc levels is frequently used in the diagnosis of a few conditions such as growth retardation, immunodeficiency, infertility, neurological disorder, and acrodermatitis enteropathica. The serum matrix is the most preferred one to determine zinc levels due to the ease of analysis with other tests and cost-effectiveness of blood collection tubes used to obtain serum samples. In our study, we aimed to compare serum and plasma zinc test results for accurate and reliable zinc measurement in plain tubes with clot activator and gel and in heparin-free tubes, which specifically produced for trace element analysis.

Method: Twenty-seven randomly selected patients were included in the study. Blood samples drawn simultaneously from patients were pipetted into tubes with clot activator and gel (SST) (SST II Advance, Vacutainer, Becton Dickinson and Company, USA) as well as into trace element tubes with sodium heparin $(\mathrm{NH})(\mathrm{NH}$ Trace Elements Sodium Heparin, Vacuette, Greiner Bio-One $\mathrm{GmbH}$, Austria). After the centrifugation process, zinc levels in serum and plasma samples were analyzed by colorimetric method using an autoanalyzer. Bias between serum and plasma zinc levels was evaluated according to the allowable bias criterion based on biological variation and regression analysis performed.

Results: The mean and standard deviation of serum and plasma zinc levels were $49.0 \pm 11.5$ $\mu \mathrm{g} / \mathrm{dL}$ and $46.4 \pm 12.0 \mu \mathrm{g} / \mathrm{dL}$, respectively, and a statistically significant difference was determined $(p=0.012)$ in between. Besides, the bias between serum and plasma was $6.8 \%$, which was above the allowable bias (3.3\%) and considered as clinically significant. No systematic or random errors detected.

Conclusions: When selecting a blood collection tube for trace element analysis, the structural differences between tubes and the matrix effect should be considered carefully.

Keywords: Zinc, plasma, serum, specimen collection
Received/Geliș: 30.11 .2020

Accepted/Kabul: 07.12.2020

Publication date: 30.12 .2020

Sema Kardeșler

SBÜ Tepecik Eğitim ve Araştırma Hastanesi Tıbbi Biyokimya Kliniği, İzmir - Türkiye

sema.kardesler@saglik.gov.tr ORCID: 0000-0003-0345-8175

F.D. Arslan 0000-0003-0766-0303

i. Karakoyun 0000-0002-7057-171X

B. İșbilen Bașok 0000-0002-1483-997X

A. Colak 0000-0003-4910-0128

SBü Tepecik Eğitim ve Araştırma Hastanesi, Tıbbi Biyokimya Kliniği, İzmir, Türkiye 


\section{Giriș}

Çinko (Zn) demirden sonra hem vücudumuzda hem intrasellüler olarak en fazla bulunan eser elementtir. ${ }^{1}$ Yaklaşık \%85'i kas ve kemikte, \%11'i deri ve karaciğerdedir. Plazmada çinkonun çoğu albumin ve alfa-2 makroglobuline bağlı bulunur. ${ }^{2}$ Enzim kofaktörü olarak hücre büyümesi, gelişim ve diferansiyasyon, DNA sentezi ve RNA transkripsiyonu gibi çeşitli biyolojik fonksiyonlarda görev alır. Yara iyileşmesi, kemik mineralizasyonu, tiroid fonksiyonu, kan pıhtılaşması, fetal büyüme, immun sistem, oksidatif stres, apoptozis, bilişsel fonksiyonda kritik öneme sahiptir. ${ }^{3,4}$ Proteinlerde, hücre membranlarında, nükleik asit ve ribozomlarda yapisal element olarak da bulunur. ${ }^{5}$

Zn ölçümü, büyüme geriliği, immun yetmezlik, infertilite, nörolojik bozukluk, akrodermatitis enteropatika gibi hastalık durumunda sık yapılan bir testtir. Nadir de olsa toksisitesi gastrointestinal belirtiler oluşturabilir. ${ }^{6}$ Klinik ve Laboratuvar Standartları Enstitüsünün (CLSI) "İz Element Tayininde Preanalitik Değişimin Kontrolü-C38-A" isimli kılavuzunda, eser element ölçümü için tam kan, serum ve plazma matrikslerinden herhangi birini önerse de buradaki temel unsur kullanılan malzemenin ekzojen kaynaklı olarak kontaminasyona neden vermemesidir. Kontaminasyonu önlemek için özel üretilmiş eser element tüpleri tercih edilmelidir. ${ }^{7}$ Birçok laboratuvarda $\mathrm{Zn}$ ölçüm için diğer testlerle birlikte analiz kolaylığı ve maliyet etkinliği nedeniyle rutin biyokimyasal testlerin çalışıldığı serum tüpleri kullanılmaktadır. Bu çalışmada, rutinde kullanılan tüplerdeki serum $\mathrm{Zn}$ ile eser element ölçümü için özel üretilmiş tüplerdeki plazma $\mathrm{Zn}$ sonuçlarının karşılaştırılması amaçlanmıştır.

\section{GEREC ve YÖNTEM}

Çalışmaya rastgele seçilmiş 27 hasta dahil edildi. Hastalardan eşzamanlı hem pıhtı aktivatörlü jelli tüplere (SST) (SST II Advance, Vacuteiner, Becton Dickinson and Company, ABD) hem sodyum heparin içeren eser element tüplerine $(\mathrm{NH})(\mathrm{NH}$ Trace Elements Sodium Heparin, Vacuette, Grenier Bio-One $\mathrm{GmbH}$, Avusturya) kan alındı. Tüplerin fiziksel özellikleri Tablo 1'de belirtildi. SST tüpleri kanının pıhtılaşması için $30 \mathrm{dk}$. oda sıcaklığında bekletildikten sonra, $\mathrm{NH}$ tüpleri ise bekletilmeden 1.200 g'de $10 \mathrm{dk}$. santrifüj edildi. Elde ettiğimiz serum ve plazma $\mathrm{Zn}$ düzeyleri otoanalizörde ( $\mathrm{AU}$ 5800, Beckman Coulter Inc., ABD) kolorimetrik yöntem (Sentinel Diagnostic, İtalya) ile çalışıldı. Serum ve plazma $\mathrm{Zn}$ düzeyleri arasındaki bias, biyolojik varyasyon kaynaklı izin verilebilir bias kriterine göre değerlendirildi. Sonuçlar arasındaki farkın istatistiksel anlamlılığı verilerin dağılımına göre paired $T$ test ile analiz edildi. Sonuçlar arasındaki ilişki Pearson korelasyon testi, Passing\&Bablok regresyon analizi ile değerlendirildi ve Blant\&Altman grafiği ile görselleştirildi (Grafik 1).

Tablo 1. Pıhtı aktivatörlü jelli tüp (SST) ve sodyum heparin içeren eser element (NH) tüplerinin fiziksel özellikleri.

\begin{tabular}{lll}
\hline & SST & NH \\
\hline Ayırıcı jel & Polimer jel & Yok \\
İç kaplama & Silikon & Yok \\
Tüp duvarı & Polietilen tetraflat & Polietilen tetraflat \\
Pıhtı aktivatörü & Silika & Yok \\
Rubber Stopper & Silikon & Brom butil \\
Antikoagülan & Yok & Sodyum heparin \\
& & \\
\hline
\end{tabular}
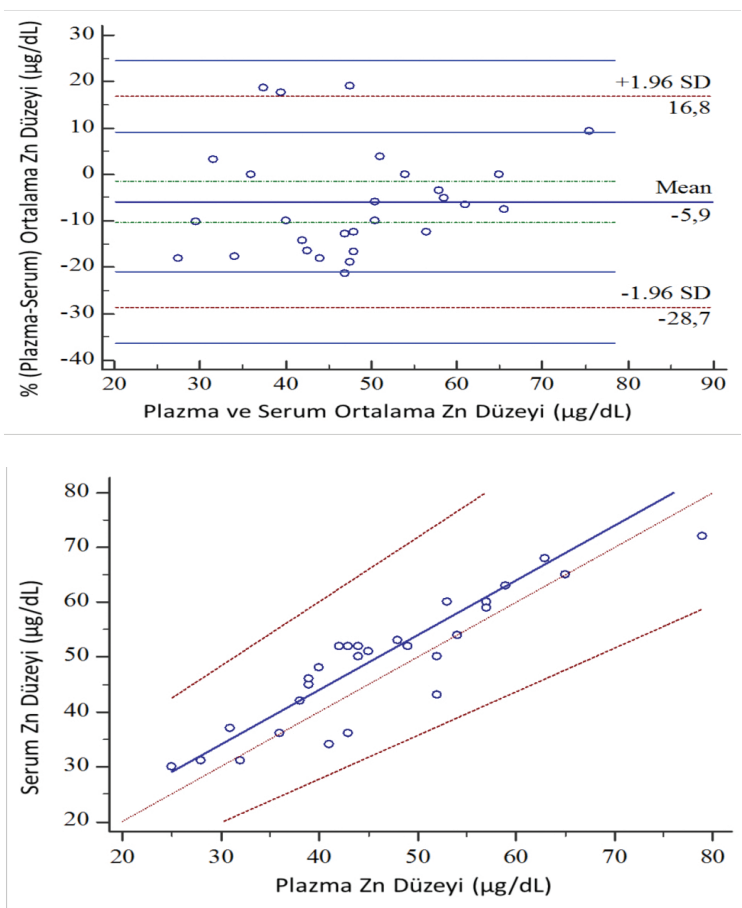

Grafik 1. Serum ve plazma Zn düzeyleri için Passing\&Bablok Regresyon analizi ve Blant\&Altman grafiği. 
Çalışma için etik kurul onayı alınmıştır (Tarih: 06.10.2016, Karar No: 2016/26-32).

\section{BULGULAR}

Serum ve plazma $\mathrm{Zn}$ düzeyleri sırasıyla $49,0 \pm 11,5$ $\mu \mathrm{g} / \mathrm{dL}$ ve $46,4 \pm 12,0 \mu \mathrm{g} / \mathrm{dL}$ olarak bulundu ve arasında anlamlı fark saptandı $(p=0,012)$. Ayrıca serum ve plazma arasındaki bias $\% 6,8$ olup, izin verilebilir biasın $(\% 3,3)$ üzerindeydi ve fark klinik açıdan anlamlı kabul edildi. Bununla birlikte, regresyon analizine göre serum ve plazma $Z n$ değerleri arasında sistematik ya da rastlantısal hata saptanmadı, hatta güçlü bir ilişki olduğu belirlendi. Serum ve plazma $\mathrm{Zn}$ sonuçlarının istatistiksel karşılaştırma bulguları Tablo 2'de gösterildi.

Tablo 2. Serum ve plazma örneklerindeki çinko $(\mathrm{Zn})$ düzeyleri, bias ve $p$ değerleri.

\begin{tabular}{lll}
\hline & \multicolumn{1}{c}{ Serum } & \multicolumn{1}{c}{ Plazma } \\
\hline Ortalama \pm Standart sapma $(\mu \mathrm{g} / \mathrm{dL})$ & $49,0 \pm 11,5 \quad 46,4 \pm 12$ \\
& $\begin{array}{l}\text { Serum ve plazma } \mathrm{Zn} \\
\text { düzeylerinin }\end{array}$ \\
& karşılaştırması \\
& 6,8 \\
Bias (\%) & 0,012 \\
p değeri & $\mathrm{y}=4,000+1,000 \mathrm{x}$ \\
Regresyon denklemi & $0,800-1,173$ \\
Eğim (\%95 güven aralığı) & $-4,434-13,200$ \\
Kesim değeri (\%95 güven aralığı) & $0,904 \quad(<0,001)$ \\
Korelasyon katsayısı (p değeri) & 0,904
\end{tabular}

\section{TARTISMA}

Zn düzeyi ölçümü amacıyla yapılan çeşitli matriks karşılaştırma çalışmalarında farklı sonuçlar elde edilmiştir. Bir çalışmada, Mona Sandberg ve ark., ${ }^{8}$ kolorimetrik yöntemle $\mathrm{Zn}$ ölçümünde serum (71,9 $\mu \mathrm{mol} / \mathrm{L}$ ) (pıhtı aktivatörlü tüp, Vacuette, Grenier Bio-One $\mathrm{GmbH}$ ) ve plazma $(74,5 \mu \mathrm{mol} / \mathrm{L})$ (lityum heparin, Barricor LH Plasma tube, Becton, Dickinson and Company) arasında anlamlı farklılık bulamamışlardır. Barroso ve ark.'nın alev atomik absorsiyon spektrofotometresiyle yaptıkları çalışmada, serum $(77,8 \mu \mathrm{g} / \mathrm{dL}$ ) (SST tube, Terumo Corporation) ve plazma $(77,4 \mu \mathrm{g} / \mathrm{dL})$ (Na heparin trace element tube, Becton Dickinson and Company) $\mathrm{Zn}$ düzeyleri arasında anlamlı fark gösterilmemiştir. Yine alev atomik absorbsiyon spektrofotometresi ile yapılan bir çalışmada, serum ile plazma arasında anlamlı farklılık bulunmamıştır. ${ }^{10}$ Wei-jie ve ark. ${ }^{11}$ atomik absorbsiyon spektrofoto- metresi ile yaptıkları çalışmada, serum $(87,3 \mu \mathrm{g} /$ $\mathrm{dL})$ ve plazma $(89,6 \mu \mathrm{g} / \mathrm{dL})$ arasında anlamlı farklılık bulmamışlardır. Foley ve ark. ${ }^{12}$ serumda plazmadan $\% 16$ daha yüksek $\mathrm{Zn}$ düzeyi bulmuşlar ve bunun pihtılaşma sırasında trombositlerden Zn'nun salınmasının nedeni ile olduğunu belirtmişlerdir. Yapılan çalışmalarda, trombositin $\mathrm{Zn}$ içeriğinin plazmanın 30-60 katı olduğu gösterilmiştir. ${ }^{13,14}$ Kasperek ve ark. da, ${ }^{15}$ plazmaya göre serumda ortalama $20 \mathrm{ng} / \mathrm{mL}$ daha yüksek Zn düzeyi bulmușlardır. Kraus ve ark. ${ }^{16}$ santrifüjden sonraki ilk 8 saatte serum (Sarstedt S-Monovette Z-gel) Zn değerlerini plazmaya göre (Sarstedt S-Monovette LH-Gel ve Sarstedt S-Monovette Metal Analysis) \%2,3 ve \%1,6 yüksek saptamışlardır. Ivanova ve ark. ${ }^{17}$ istatiksel olarak anlamlı olmasa da serum $(70,0 \mu \mathrm{g} / \mathrm{dL})$ (Trace Element Tube Serum, Becton Dickinson and Company) ve plazma (70,2 $\mathrm{\mu g} / \mathrm{dL}$ ) (Trace Element Tube, K2 EDTA, Becton Dickinson and Company) Zn sonuçlarını, Li Heparinli plazmaya $(67,0 \mu \mathrm{g} /$ dL) (Barricor Li Heparin, Becton, Dickinson and Company) göre daha yüksek bulmuşlardır. Serumdaki yüksekliği pıhtılaşma sırasında eritrosit ve trombositten salınımına, EDTA'lı tüpteki yüksekliği de antikoagülan EDTA'dan Zn'nun sızmasına bağlamışlardır. Daha düşük plazma $\mathrm{Zn}$ konsantrasyonunun fazla heparin ya da sitrat kullanımına bağlı olduğunu söyleyen çalışmalar vardır. ${ }^{18-}$ ${ }^{20}$ Ancak, başka bir çalışmada, heparin kullanımının plazma $\mathrm{Zn}$ düzeyini etkilemediğini belirtilmiştir. $^{21}$

Çalışmamızda, serum $\mathrm{Zn}$ düzeyini plazmadan $\% 6,8$ daha yüksek bulduk. Tablo 1 'de belirttiğimiz gibi her iki tüp için de ortak olan özellik tüpün duvar yapısı olan "polietilen tetraflat (PET)"dır. Her 2 tüpün duvar yapısı PET olduğundan, bu interferansın nedeninin, jelli tüpte serumda bulunan Zn'nun separatör jel, silika, silikon, "rubber stopper" dan emilimi ya da bu maddelerden seruma $\mathrm{Zn}$ salınımı ve pıhtı oluşumu sırasında trombositlerden kaynaklanan $\mathrm{Zn}$ olabileceğini düşündük. "Rubber stopper", kan alma tüplerine uyacak şekilde boyutlandırılmış ve antikoagülan türüne veya separatör jelin varlığına göre renk kodu olan kauçuk tıpa olup, üretiminde $\mathrm{Ca}, \mathrm{Al}, \mathrm{Mg}, \mathrm{Zn}$ kullanılmaktadır. Ancak, bu elementlerin kanla temas etmediğini bildiren yayınlar da vardır. ${ }^{17,22}$ 
Ayrıca pihtılaşma sürecinde trombositten salınan Zn'nun fibrine bağlanması da sonucu etkileyebilir. $^{23}$

\section{SONUC}

Heparin içeren ve jel bulunmayan eser element tüpünde jel, silika, silikon gibi katkı maddeleri olmaması ve serumdan faklı olarak fibrin oluşmadığından bu tüpün kullanımında olası interferans kaynakları azalmaktadır. Eser element ölçümlerinde klinik yarar açısından jelli pıhtı aktivatörlü tüplerinin kullanımı yaygın olsa da, özel olarak üretilen tüplerin kullanımının daha yararlı olacağı düşüncesindeyiz.

Etik Kurul Onayı: Dokuz Eylül Üniversitesi Girişimsel Olmayan Araştırmalar Etik Kurul onayı alındı (06.10.2016/26-32).

Çıkar Çatışması: Yok.

Finansal Destek: Yok.

Hasta Onamı: Yok.

Ethics Committee Approval: Dokuz Eylül University Non-Interventional Research Ethics Committee approval was obtained (06.10.2016/26-32).

Conflict of Interest: None.

Funding: None.

Informed Consent: None.

\section{KAYNAKLAR}

1. Miller LV, Hambidge KM, Naake VL, et al. Size of the zinc pools that exchange rapidly with plasma zinc in humans: alternative techniques for measuring and relation to dietary zinc intake. J Nutr. 1994;124(2):268-76. jn/124.2.268. PMID: 8308576.

2. Taylor A. Detection and monitoring of disorders of essential trace elements. Ann Clin Biochem. 1996;33(Pt 6):486-510. doi.org/10.1177/000456329603300603. PMID: 8937580.

3. Fukada T, Yamasaki S, Nishida K, et al. Zinc homeostasis and signaling in health and diseases: Zinc signaling. J Biol Inorg Chem. 2011;16(7):1123-34. doi.org/10.1007/s00775-011-0797-4. Epub 2011 Jun 10. PMID: 21660546; PMCID: PMC3176402.

4. Faure P. Protective effects of antioxidant micronutrients (vitamin $\mathrm{E}$, zinc and selenium) in type 2 diabetes mellitus. Clin Chem Lab Med. 2003;41(8):995-8. doi.org/10.1515/ CCLM.2003.152. PMID: 12964803.

5. Truong-Tran AQ, Ho LH, Chai F, et al. Cellular zinc fluxes and the regulation of apoptosis/gene- directed cell death. J Nutr. 2000;130(5S Suppl):1459S-66S. doi.org/10.1093/ jn/130.5.1459S. PMID: 10801960.

6. Rifai N, et al. Tietz Textbook of Clinical Chemistry and Molecular Diagnostics. six edition. 2018; p.713.

7. Lockitch, G, Fasset, J. D., Gerson, B. et al. Control of preanalytical variation in trace-element determinations; approved guideline. 1997, NCCLS document C38-A. NCCCLAS, Pensilvania.

8. Sandberg, M. Hur ska man diagnostisera zinkbrist?. How to diagnose zinc deficiency? Wågsäter Linköpings universitet|Medicinska fakulteten Examensarbete. $15 \mathrm{hp}$ Biomedicinska analytikerprogrammet Vårterminen 2016.

9. Barroso I, Farinha R, Guimarães JT. Proper zinc evaluation in clinical practice: Effect of sample type and it's stability. Clin Biochem. 2018;59:93-5. doi. org/10.1016/j.clinbiochem.2018.07.001. Epub 2018 Jul 4. PMID: 30111511.

10. Kosman DJ, Henkin RI. Plasma and serum zinc concentrations. Lancet. 1979;1(8131):1410. doi.org/10.1016/ s0140-6736(79)92047-6. PMID: 87873.

11. Chen WJ, Zhao CY, Zheng TL. Comparison of zinc contents in human serum and plasma. Clin Chim Acta. 1986;155(2):185-7. doi.org/10.1016/00098981(86)90282-2. PMID: 3698315.

12. Foley B, Johnson SA, Hackley B, et al. Zinc content of human platelets. Proc Soc Exp Biol Med. 1968;128(1):265-9. doi.org/10.3181/00379727128-32993. PMID: 5656702.

13. Marx G, Korner G, Mou X, et al. Packaging zinc, fibrinogen, and factor XIII in platelet alpha-granules. J Cell Physiol. 1993;156(3):437-42. doi. org/10.1002/jcp.1041560302. PMID: 8360253.

14. Vu TT, Fredenburgh JC, Weitz JI. Zinc: an important cofactor in haemostasis and thrombosis. Thromb Haemost. 2013;109(3):421-30. doi.org/10.1160/ TH12-07-0465. Epub 2013 Jan 10. PMID: 23306381.

15. Kasperek K, Kiem J, lyengar GV Concentration differences between serum and plasma of the elements cobalt, iron, mercury, rubidium, selenium and zinc determined by neutron activation analysis. The Science of the Total Environment. 1981;17:13343. doi.org/10.1016/0048-9697(81)90179-0

16. Kraus FB, Ludwig-Kraus B Measuring zinc on the Roche cobas $\mathrm{C} 502$ analyzer-Validation, comparison, and pre-analytic aspects. Journal of clinical laboratory analysis. 2018,;32(1): e22169. doi. org/10.1002/jcla.22169

17. Ivanova I, Atanasova B, Vodenicharov V, et al. Blood collection tubes:An aspect of preanalytical variations of copper and zinc analyses. International Journal of Current Medical and Pharmaceutical Research. 2017; 2081-4. doi. org/10.24327/23956429.ijcmpr20170159

18. Smith JC Jr, Lewis S, Holbrook J, et al. Effect of heparin and citrate on measured concentrations of various analytes in plasma. Clin Chem. 1987;33(6):814-6. PMID: 3594823.

19. Makino T. A potential problem on comparison of plasma with serum for zinc content. Clin Chem. 1983;29/6:1313-4.

20. Smith JC, Holbrook JT, Danford DE. Analysis and evaluation of zinc and copper in human plasma and 
serum. J Am Coll Nutr. 1985;4(6):627-38. doi.org/ 10.1080/07315724.1985.10720105. PMID: 4078201.

21. English JL, Hambidge KM, Goodall MJ Evaluation of some factors that may affect plasma or serum zinc concentrations. In Trace Elements in Man and Animals 6, 1988, (pp. 459-460). Springer, Boston, MA. doi.org/10.1007/978-1-4613-0723-5_159

22. van den Besselaar AM, van Dam W, Sturk $\bar{A}$, et al.
Prothrombin time ratio is reduced by magnesium contamination in evacuated blood collection tubes. Thromb Haemost. 2001;85(4):647-50. PMID: 11341499

23. Henderson SJ, Xia J, Wu H, et al. Zinc promotes clot stability by accelerating clot formation and modifying fibrin structure. Thromb Haemost. 2016;115(3):533-42. doi.org/10.1160/TH15-060462. Epub 2015 Oct 22. PMID: 26489782. 